Revista Eureka sobre Enseñanza y Divulgación de las Ciencias

ISSN: 1697-011X

revista.eureka@uca.es

Universidad de Cádiz

España

\title{
Ayudando a maestros en formación inicial a desarrollar indagaciones en la Educación Infantil
}

\author{
Alarcón Orozco, María Marta; Franco Mariscal, Antonio Joaquín; Blanco López, Ángel \\ Ayudando a maestros en formación inicial a desarrollar indagaciones en la Educación Infantil \\ Revista Eureka sobre Enseñanza y Divulgación de las Ciencias, vol. 19, núm. 1, 2022 \\ Universidad de Cádiz, España \\ Disponible en: https://www.redalyc.org/articulo.oa?id=92068491003 \\ DOI: https://doi.org/10.25267/Rev_Eureka_ensen_divulg_cienc.2022.v19.i1.1601
}




\title{
Ayudando a maestros en formación inicial a desarrollar indagaciones en la Educación Infantil
}

\author{
Helping pre-service teachers to develop inquiries in Early Childhood Education
}

Maria Marta Alarcón Orozco

Departamento de Didáctica de la Matemática, de las

Ciencias Sociales y de las Ciencias Experimentales, Facultad

de Ciencias de la Educación, Universidad de Málaga,

España

mmartaalarcon@uma.es

iD https://orcid.org/0000-0002-8353-9890

Antonio Joaquin Franco Mariscal

Departamento de Didáctica de la Matemática, de las

Ciencias Sociales y de las Ciencias Experimentales, Facultad

de Ciencias de la Educación, Universidad de Málaga,

España

antoniojoaquin.franco@uma.es

iD https://orcid.org/0000-0002-8704-6065

Ángel Blanco López

Departamento de Didáctica de la Matemática, de las

Ciencias Sociales y de las Ciencias Experimentales, Facultad

de Ciencias de la Educación, Universidad de Málaga,

España

ablancol@uma.es

(DD https://orcid.org/0000-0003-3628-0801
DOI: https://doi.org/10.25267/

Rev_Eureka_ensen_divulg_cienc.2022.v19.i1.1601

Redalyc: https://www.redalyc.org/articulo.oa?

$\mathrm{id}=92068491003$

Recepción: 29 Julio 2020

Revisado: 03 Marzo 2021

Aprobación: 30 Julio 2021

\section{ReSUMEN:}

La indagación se presenta como un enfoque adecuado para iniciar la alfabetización científica en edades tempranas. La formación inicial de maestros se considera como un aspecto clave para llevar la indagación a las aulas de Educación Infantil. Sin embargo, son escasos los programas específicos de indagación que incluyen la transferencia a la práctica para formar a maestros de esta etapa educativa. Este trabajo presenta los fundamentos, principios de diseño y secuencia de actividades de un programa formativo centrado en la indagación para estudiantes del Grado en Educación Infantil que integra la formación académica y profesional. Se ha desarrollado en dos centros de formación distintos enmarcado en las asignaturas de Didáctica de las Ciencias de la Naturaleza, Practicum III y Trabajo Fin de Grado. El trabajo muestra la valoración que los participantes hacen del uso de la indagación en la Educación Infantil. El análisis de esta valoración nos permite hacer propuestas de mejora sobre el propio programa.

PALABRAS ClAVE: Indagación, formación inicial de maestros, Educación Infantil, formación académica y profesional, transferencia a la práctica.

\section{ABSTRACT:}

Inquiry is presented as an appropriate approach to initiate scientific literacy at early ages. Initial teacher training is considered a key aspect of bring inquiry into Early Childhood classrooms. However, there are few specific inquiry programmes including transfer to practice in order to train teachers at this stage of education. This paper presents the foundations, the design principles and the sequence of activities of an inquiry-based training programme for Early Childhood pre-service teachers integrating academic 
and professional training. It has been developed in two different training centers framed in the subjects of Natural Science Education, Practicum III and Final Degree Project. The assessment that the participants make of the use of the inquiry in Early Childhood Education is presented in this paper. The analysis of this assessment allows us to make proposals in order to improve the programme.

KEYWORDS: Inquiry, initial teacher training, Early Childhood Education, academic and vocational training, transfer to practice.

\section{INTRODUCCIÓN}

La enseñanza de las ciencias basada en la indagación ha cobrado interés como enfoque didáctico en los últimos años a raíz de la publicación de distintos informes internacionales (Rocard 2007, Nuffield 2008, COSCE 2011) que consideran necesario transformar la forma de enseñar ciencias, pasando de metodologías tradicionales, centradas en la trasmisión de conocimientos, a otras basadas en el desarrollo de prácticas científicas, como la indagación, que favorecen el interés por la ciencia en el alumnado y estimulan la motivación del docente (Osborne y Dillon 2008).

La Educación Infantil (EI) es una etapa educativa con identidad propia que contribuye al desarrollo físico, afectivo, social e intelectual de los niños y niñas ${ }^{[1]}$ desde el nacimiento hasta los seis años (MEC 2007) que debe abordar la necesidad de una alfabetización científica básica desde edades tempranas (COSCE 2011). La curiosidad de los niños y su disposición para comprender el mundo que les rodea pueden verse como fuerzas impulsoras para aprender ciencias en estos primeros años. Cañal (2006) considera vital esta etapa para promover entre los escolares una primera aproximación a las perspectivas científicas sobre la realidad. La indagación se considera un enfoque adecuado para acercar a los niños de estas edades a la realidad científica ya que uno de sus rasgos característicos es el papel activo de los estudiantes al involucrarse en la resolución de problemas para aprender ciencias (Toma et al. 2017).

La principal dificultad que plantea la implementación de la indagación en las aulas de EI es la falta de confianza de los maestros de la etapa en sus conocimientos científicos (Sáez 2017). Estudios previos ponen de manifiesto que este conocimiento limitado está directamente relacionado con la confianza en su competencia para enseñar estas materias (Fleer 2009), lo que significa que las opiniones de los maestros sobre los niños, sobre cómo aprenden y la visión que tienen de sí mismos se refleja en las posibilidades de los niños para aprender (Thulin y Redfors 2016). Estas cuestiones nos llevan a considerar la importancia de la formación de los maestros de EI, tanto inicial como permanente, no solo en conocimientos, habilidades y destrezas sino también en sus actitudes hacia las ciencias y ante propuestas metodológicas innovadoras para su enseñanza. Toma et al. (2017) afirman que para que los maestros en formación puedan aplicar adecuadamente estas metodologías deben disponer de conocimientos apropiados.

Por otra parte, una de las mayores dificultades que presentan los estudiantes del Grado en Educación Infantil (EGEI) que reciben formación sobre indagación es la transferencia de lo aprendido al aula. Esta situación genera la denominada brecha formación-práctica (Blanco-López 2019) de la que hacen eco autores como Martínez-Chico et al. (2020) y tiene como consecuencia un distanciamiento entre los resultados de investigación didáctica y la formación del profesorado y la práctica docente. De ahí la necesidad de diseñar, implementar y evaluar programas formativos para maestros que sean integradores y que faciliten y apoyen la transferencia a la práctica.

En este sentido, si bien en la literatura existen algunos programas para la formación de maestros sobre indagación (Windschitl 2002, Martínez-Chico et al.2015, Toma et al. 2017 y Mesci et al. 2020) aún siguen siendo escasos los trabajos, como los de Eckhoff (2017) o López-Luengo et al. (2018), que aborden de forma simultánea la formación académica y la transferencia a la práctica educativa en EI.

En esta línea, la finalidad de este trabajo es presentar un programa formativo centrado en la indagación para EGEIs, en el que se combina una formación académica y profesional, pretendiendo con ello favorecer la transferencia a la práctica. 


\section{Marco Teórico}

\section{La indagación en la Educación Infantil}

El informe ENCIENDE (COSCE 2011) propone comenzar la educación científica a los 3 años argumentando que este hecho favorece el interés hacia la ciencia y la cultura científica de los ciudadanos (p.49). Estas consideraciones están en consonancia con investigaciones que ponen de manifiesto que los niños son capaces de utilizar procesos fundamentales para el pensamiento científico (Zembal-Saul 2009, Ünver $e t$ al. 2016) en contraposición a posturas anteriores que, siguiendo las teorías piagetianas, sostenían que éste no era asequible a las capacidades de los niños. Los niños de EI se caracterizan por mostrar curiosidad por todo lo que les rodea, y por su necesidad de manipular e interactuar con los elementos que tienen alrededor tratando de descubrir qué son o cómo funcionan. Worth (2010) considera que estas características se convierten, con la orientación adecuada, en la base para comenzar a utilizar las habilidades de indagación que permiten explorar fenómenos y materiales básicos del entorno próximo de forma que los nuevos conocimientos adquiridos sean significativos para el niño y las indagaciones realizadas resulten productivas (Samarapungavan et al. 2008). Estas cuestiones hacen que las edades entre 3 y 6 años sean un momento clave para comenzar una aproximación a la ciencia.

Por otra parte, considerando las peculiaridades de esta etapa educativa, Cantó et al. (2016) afirman que las ciencias en EI deberían centrarse más en las habilidades propias del trabajo científico y en la creación de hábitos y actitudes que en contenidos específicos y disciplinares. Estas premisas nos permiten pensar que el aprendizaje basado en la indagación es uno de los enfoques más apropiados para iniciar a los niños en la alfabetización científica. La literatura muestra cómo las propuestas pedagógicas sobre indagación han cobrado importancia en los últimos años (Samarapungavan et al. 2008, Lederman et al. 2013, Romero-Ariza 2017), aunque su presencia en las aulas aún es escasa (Cantó et al. 2016, Aguilera et al. 2018, Mosquera et al. 2018). La falta de formación del profesorado es una de las razones, de ahí la importancia de formarlo adecuadamente para poder implementar en el aula indagaciones de calidad.

\section{La indagación en la formación inicial de maestros de infantil en España}

Diferentes estudios se han centrado en conocer los puntos de partida de los EGEIs con respecto a sus creencias y expectativas sobre la ciencia y su enseñanza entendiendo que son aspectos importantes que influirán en su formación docente y en su futura práctica profesional. Los estudios muestran que los EGEIs poseen un conocimiento limitado de los contenidos de ciencias y de sus procesos elementales (Verdugo et al. 2019), siendo su interés por estas cuestiones generalmente bajo y llegando incluso a mostrar animadversión por las mismas (Cruz-Guzmán et al. 2020). Este rechazo puede estar asociado a experiencias previas negativas como estudiantes en las que ha predominado un modelo de enseñanza de las ciencias que «ha consistido en trasmitir conocimientos elaborados más que en favorecer la construcción de ideas por parte del alumnado» (Sáez 2017, p.2214).

Esta situación genera en los EGEIs sentimientos de inseguridad y desconfianza al abordar contenidos científicos, que limita la realización de actividades de ciencias en el aula (Erden y Sönmez 2011). En este sentido, coincidimos con López-Luengo et al. (2018) cuando afirman que durante la formación inicial del docente «es necesario no solo mejorar la competencia científica, sino, fundamentalmente, la relación establecida con las ciencias durante la educación secundaria, reduciendo en lo posible miedos, complejos y rechazos, en todos los ámbitos científicos y también en el tecnológico» (p.7). Así, si el futuro docente mantiene una actitud de distanciamiento hacia las ciencias, difícilmente podrá favorecer y potenciar el interés infantil por estas cuestiones (Crawford 2007). 
Los EGEIs no pueden comprender las prácticas científicas, ni apreciar plenamente la naturaleza del conocimiento científico en sí mismo, sin experimentarlas directamente (NRC 2012). Por tanto, hay que dar la oportunidad de trabajar de un modo similar a como lo hacen los científicos en la resolución de problemas, permitiéndoles familiarizarse con el trabajo científico y adquirir una comprensión procedimental de la ciencia utilizando destrezas y procedimientos propios de la indagación científica en un marco escolar. Como docentes e investigadores, debemos ayudar a los EGEIs en la elaboración y uso de secuencias didácticas con enfoque indagativo (Caamaño 2012).

Otra cuestión importante, para invertir la actitud de distanciamiento de los EGEIs hacia las ciencias y favorecer la transferencia al aula, es que los futuros maestros reflexionen sobre lo que han aprendido y tomen conciencia de las emociones que han sentido durante el proceso de aprendizaje. En este sentido, investigaciones recientes muestran que «las emociones que se experimentan en el aula (satisfacción, inseguridad, alegría, aburrimiento...) están significativamente relacionadas con logros académicos» (LópezGay et al. 2020, p.42). El objetivo, compartido con Martínez-Chico et al. (2019), es enganchar a los EGEIs para que participen no solo en el proceso para desarrollar una comprensión de las ideas básicas disciplinarias, sino principalmente para adquirir una comprensión procesal y epistémica, favoreciendo así su participación en investigaciones útiles para su práctica docente.

\section{OвJetivos}

Este trabajo pretende:

A. Describir los fundamentos, los principios de diseño y la secuencia de actividades de un programa formativo sobre indagación para EGEIs que integra la formación académica con la profesional.

B. Analizar la valoración que hacen los EGEIs del uso de la indagación en la EI.

\section{CONTEXTO FORMATIVO}

Han participado en este estudio 133 EGEIs de dos centros de la Universidad de Málaga: la Facultad de Ciencias de la Educación (CCEE, $\mathrm{N}=80$ ) y el Centro Adscrito de Magisterio María Inmaculada de Antequera (CAMMIA, $\mathrm{N}=53$ ). Como suele ser habitual en el perfil de esta titulación, todos los participantes eran chicas excepto dos chicos pertenecientes a la Facultad de CCEE.

El programa formativo se desarrolló durante los cursos académicos 2018-19 y 2019-20 en tres asignaturas: Didáctica de las Ciencias de la Naturaleza ( 8 créditos, segundo cuatrimestre del tercer curso), Prácticum III (30 créditos, primer cuatrimestre del cuarto curso) y Trabajo Fin de Grado (TFG) (6 créditos, segundo cuatrimestre del cuarto curso). Entre las competencias específicas de la asignatura de Didáctica de las Ciencias de la Naturaleza destacan conocer la metodología científica y promover el pensamiento científico y la experimentación; elaborar propuestas didácticas en relación con la intervención ciencia, técnica, sociedad y desarrollo sostenible; y promover el interés y el respeto por el medio natural, social y cultural a través de proyectos didácticos ${ }^{[2]}$. Las asignaturas de Prácticum III y TFG ${ }^{[3]}$ desarrollan competencias específicas entre las que destacan dominar las destrezas y habilidades sociales necesarias para fomentar un clima que facilite el aprendizaje y la convivencia; controlar y hacer el seguimiento del proceso educativo y, en particular, de enseñanza-aprendizaje mediante el dominio de técnicas y estrategias necesarias; participar en la actividad docente y aprender a saber hacer, actuando y reflexionando desde la práctica; y desarrollar las propuestas de mejora en los distintos ámbitos de educación que se puedan establecer en un centro. La evaluación de una propuesta formativa realizada por el EGEI, así como su implementación en EI constituye el tema central de los TFG. 
El programa fue desarrollado en cada centro educativo por un formador diferente. Ambos docentes (los dos primeros autores de este trabajo) son investigadores en Didáctica de las Ciencias Experimentales. Asimismo, realizaron un seguimiento de la implementación de forma coordinada en los dos centros, para que la puesta en práctica se realizara de la forma más semejante posible. No obstante, es necesario indicar que CAMMIA tiene un convenio de colaboración con una escuela de EI en la que los EGEIs realizan habitualmente diferentes experiencias en las asignaturas didácticas del Grado.

\section{DISEÑO Y DESARROLLO DEL PROGRAMA FORMATIVO}

La Figura 1 resume el proceso de diseño y desarrollo del programa formativo, en el que se ha diferenciado dos partes denominadas formación académica y formación profesional respectivamente. El diseño y desarrollo de la formación académica tuvo una duración de un semestre, mientras que la formación profesional tuvo una duración de cinco meses desde la fase de diagnóstico hasta la entrega del informe de TFG.

\begin{tabular}{|c|c|c|c|c|c|c|c|}
\hline \multicolumn{8}{|c|}{ Primer Año: Formación Académica } \\
\hline Mes I.0 & Mes I.1 & Mes 1.2 & & & Mes I.4 & Mes 1.5 & Mes 1.6 \\
\hline $\begin{array}{c}\text { Toma de } \\
\text { decisiones y } \\
\text { Diseño de la } \\
\text { Formación } \\
\text { Académica }\end{array}$ & \multicolumn{2}{|c|}{$\begin{array}{l}\text { Valoración de Intereses e Ideas } \\
\text { previas de los EGEls }\end{array}$} & & $\begin{array}{l}\text { del } \\
\text { ama } \\
\text { vo de } \\
\text { ción }\end{array}$ & \multicolumn{3}{|c|}{ Desarrollo y Evaluación de la Formación Académica } \\
\hline \multicolumn{8}{|c|}{ Segundo Año: Formación Profesional } \\
\hline Mes II.0 & Mes II.1 & \multicolumn{2}{|c|}{ Mes II.2 } & \multicolumn{2}{|c|}{ Mes II.3 } & Mes II.4 & Mes II.5 \\
\hline $\begin{array}{c}\text { Toma de } \\
\text { decisiones y } \\
\text { Diseño de la } \\
\text { Formación } \\
\text { Profesional }\end{array}$ & $\begin{array}{c}\text { Fase de } \\
\text { Diagnóstico }\end{array}$ & \multicolumn{2}{|c|}{$\begin{array}{l}\text { Entrega de la } \\
\text { Propuesta } \\
\text { Didáctica }\end{array}$} & \multicolumn{2}{|c|}{$\begin{array}{l}\text { Devolución de la } \\
\text { Propuesta } \\
\text { Didáctica } \\
\text { revisada }\end{array}$} & $\begin{array}{l}\text { Implementación } \\
\text { de la Propuesta }\end{array}$ & $\begin{array}{l}\text { Entrega del } \\
\text { Informe Final }\end{array}$ \\
\hline
\end{tabular}

FIGURA 1

Cronograma del diseño y desarrollo del programa formativo

A continuación, se describen las distintas partes del programa formativo.

\section{FormaCión ACADÉMiCA}

\section{Toma de decisiones y diseño de la formación académica}

Se llevó a cabo un conjunto de reuniones de los investigadores en las que se acordaron directrices conjuntas para diseñar el programa formativo, entre las que destacan la importancia de hacer explícitos los principios en los que debería basarse el programa formativo y, partir de un esquema que ya se había mostrado válido para la formación inicial de profesorado de secundaria (España et al. 2013) adaptándolo a EGEIs. También la necesidad de evaluar tanto la percepción como las habilidades de los EGEIs sobre indagación en la etapa de EI, así como propiciar la interrelación entre el alumnado fomentando la colaboración entre ellos. Además, se consideró conveniente valorar las emociones vividas por los EGEIs durante el desarrollo del programa y también sus percepciones respecto a su propio aprendizaje (López-Gay et al. 2020). Por último, se tuvo en cuenta la incorporación de recursos tecnológicos (campus virtual, programas colaborativos y de gestión de la información, etc.) tanto en la implementación del programa como en los proyectos de indagación de los EGEIs, así como los recursos disponibles en los laboratorios de ciencias de los centros de formación implicados. 


\section{Valoración de intereses e ideas previas de los EGEIs}

Para evaluar la percepción y habilidades de los EGEIs sobre la indagación en la etapa de EI, así como sus conocimientos científicos, se diseñó un cuestionario que incluía una pregunta directa sobre la posibilidad de enseñar ciencias y desarrollar indagaciones científicas en esta etapa y una batería más amplia de preguntas sobre alfabetización científica básica seleccionadas de las Encuestas de Percepción Social de la Ciencia y la Tecnología (FECYT 2017). Este instrumento serviría además para conocer los temas de ciencias sobre los que tenían un mayor interés y poder diseñar una secuencia de indagación cercana a dichos intereses.

Previo al diseño del programa formativo se consideró también importante conocer el grado de comprensión de los EGEIs sobre la indagación científica. Para ello, se utilizó el instrumento Views About Scientific Inquiry (VASI) (Lederman et al. 2014) diseñado para medir el grado de comprensión de los aspectos de la indagación científica en estudiantes K-16 y que también se puede aplicar a estudiantes universitarios (Lederman et al. 2019).

\section{Diseño del programa formativo académico sobre indagación}

Las decisiones tomadas en el diseño del programa formativo académico se basaron en cinco principios de diseño:

(a) Partir de la situación inicial de los EGEIs con respecto a su formación cientifica

La situación inicial de los EGEIs se estableció a partir de las respuestas dadas al cuestionario descrito en el apartado anterior. El 78,5\% había cursado Bachillerato, pero solo en un caso éste fue de ciencias. Este dato es significativo porque confirma que la mayoría posee una formación previa centrada en las Ciencias Sociales y un bajo nivel de conocimientos de ciencias, como se mencionó anteriormente. Si bien todos los EGEIs consideraron que se puede enseñar ciencias en EI, tres de ellas pensaban que los niños de esta edad no podían hacer investigaciones porque aún son pequeños o porque son complicadas. En algún caso también pensaban que podían realizar investigaciones con ayuda de la maestra. Estas creencias sobre esta falta de capacidad de los niños para realizar indagaciones se tuvieron en cuenta en el diseño del programa formativo introduciendo, antes de que las EGEIs diseñaran su proyecto de indagación, ejemplos de su viabilidad mostrando actividades de indagación con niños de EI.

(b) Integrar la formación cientifica y didáctica sobre la indagación

De acuerdo con Hanuscin et al. (2011) y Mesci et al. (2020), los conocimientos generales de didáctica y la comprensión del tema no son suficientes en el ámbito de las ciencias, siendo necesario combinar la didáctica con el contenido científico específico, así como con otros dominios del conocimiento del aprendizaje. Por ello, la formación científica del programa incluía una introducción a la indagación presentando un modelo sobre cómo entenderla en el ámbito escolar (Franco-Mariscal 2015) y un proyecto de indagación guiada (Alarcón-Orozco et al. 2021). Tras la formación científica se lleva a cabo la formación didáctica sobre indagación que incluye el análisis didáctico de actividades de indagación, antes de comenzar un ciclo de diseño, desarrollo y evaluación de una propuesta didáctica para niños de EI.

(c) La necesidad de que los EGEIs vivencien las actividades de indagación

El hecho de que la mayoría de EGEIs hubiesen manifestado que no habían realizado actividades de indagación en su etapa escolar plantea un obstáculo para su formación al no tener un conocimiento experiencial con el que relacionar la formación científico-didáctica que se pretende dar. Mientras persista esta situación consideramos necesario que los EGEIs vivencien ciclos de indagación completos previamente a su formación didáctica. Así, en este programa los EGEIs realizan un ciclo de indagación para responder a la pregunta inicial ¿cuál es la mejor forma de elaborar yogur? (Muñoz-Campos et al.2020). La Figura 2 presenta las etapas de la indagación indicando sus fases (en azul) y los procedimientos asociados (en rojo). 

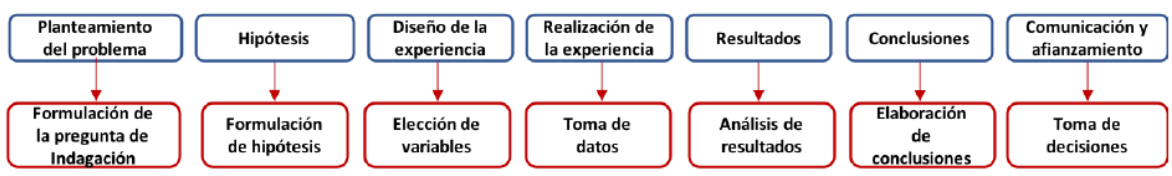

FIGURA 2

Secuencia completa de indagación adaptada de Alarcón-Orozco et al. (2021)

De esta forma se involucra a los EGEIs en experiencias prácticas siguiendo la metodología de indagación propuesta por el National Research Council (NRC 2012). Conlleva la formulación y comprobación de hipótesis, la resolución de un problema real y la construcción de explicaciones del fenómeno estudiado a partir del análisis y la interpretación de datos y la síntesis de sus propias ideas. Investigaciones previas (Windschitl 2002, Haefner y Zembal - Saul 2004, Toma et al. 2017) ponen de manifiesto cómo los EGEIs pueden llegar a cambiar su concepción sobre la naturaleza de la ciencia si participan en indagaciones escolares durante su formación.

\section{(d) Incluir la transferencia a la práctica como un aspecto clave en la formación inicial de maestros}

La formación académica no garantiza por sí sola que los EGEIs sean capaces, en su práctica profesional, de desarrollar propuestas de indagación con niños de EI (Toma et al. 2017). Además de la formación en indagación es necesario que los futuros maestros ganen confianza en sí mismos, lo que implica incluir en sus programas formativos la transferencia a la práctica (López-Luengo et al. 2018). En este momento se considera que los EGEIs ya están en disposición de transferir la formación académica recibida a la práctica escolar, diseñando, implementando y evaluando de forma autónoma, un proyecto de indagación para EI. El papel de los formadores en esta etapa consiste en acompañar y tutorizar a los EGEIs en estas tareas durante la realización de sus prácticas externas, que consideramos que es el momento idóneo para su desempeño. Esta compleja tarea supone ayudar a que los EGEIs cuestionen, reinterpreten, replanteen y sistematicen sus propias experiencias y aprendizajes (Hernández et al. 2013).

(e) Incluir la reflexión sobre el aprendizaje y las emociones

Estudios de ámbito nacional (Costillo et al. 2013) e internacional (Yeigh et al. 2016) destacan la influencia de las emociones en los procesos de enseñanza-aprendizaje. Por ello, es importante ayudar a los EGEIs a desarrollar una mayor conciencia sobre sus emociones con relación a las ciencias y sobre cómo influyen en su confianza pedagógica. Además, resulta significativo valorar la evolución de las emociones sentidas por los EGEIs antes, durante y después del proceso formativo. Por este motivo, a lo largo del programa, se incluyeron cuatro actividades de reflexión y autorregulación de aprendizajes y emociones (Jiménez-Liso et al. 2018) denominadas Reflexión sobre emociones para incentivar que los EGEIs reflexionen sobre lo que sienten y aprenden y cómo lo aprenden. Estas actividades permiten a los formadores comprobar si aumenta o no la confianza de los EGEIs para implementar proyectos de indagación en el aula de EI. El programa también incluye una actividad de reflexión final sobre ventajas e inconvenientes de la indagación en EI.

\section{Secuencia de actividades de la formación académica}

Tomando en consideración los cinco principios de diseño y el esquema propuesto por España et al. (2013), se presenta en la Figura 3 el flujograma de la formación académica, que consta de ocho etapas. 


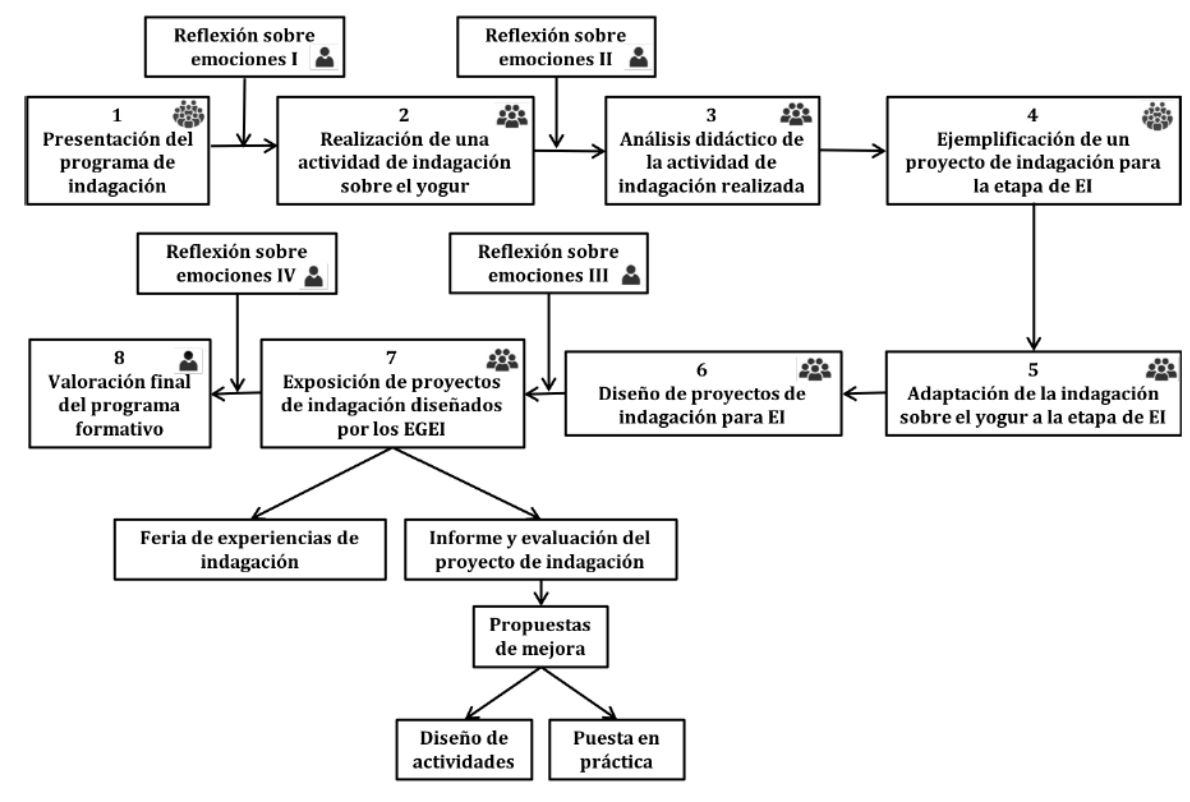

FIGURA 3

Flujograma de la formación académica del programa para EGEIs (adaptado de Alarcón-Orozco et al. 2019)

Como se observa en los distintos iconos de la Figura 3, y se ilustra con imágenes en la Figura 4, el programa incluye actividades orientadas al grupo clase, al trabajo individual y al trabajo en equipo. Se adoptó una estructura cooperativa de aprendizaje en la que se organiza el ambiente de trabajo decidiendo el número de miembros de los Equipos de Trabajo (ET) y los agrupamientos de EGEIs, estableciendo las normas y distribuyendo los roles en el alumnado (Alarcón-Orozco y Reguero 2018).

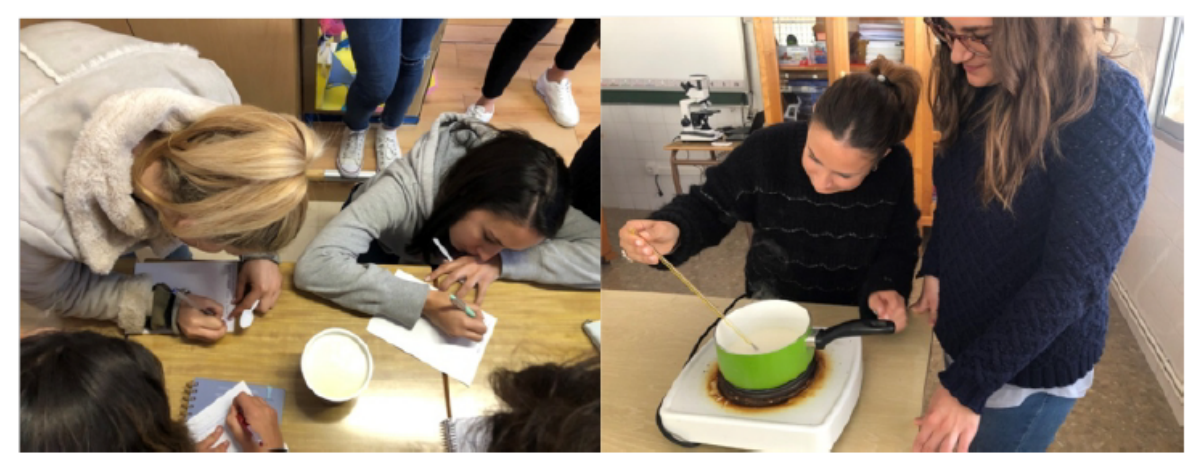

FIGURA 4

EGEIs realizando actividades durante el programa formativo

Para facilitar la interrelación entre los EGEIs de los dos centros de formación, se organizó una feria de experiencias de indagación (Figura 5) en la que los ET de ambos centros intercambiaron experiencias y compartieron sus proyectos de indagación. De esta forma, comunicando y difundiendo sus resultados de investigación, se facilita a los EGEIs una primera aproximación a la transposición didáctica. 


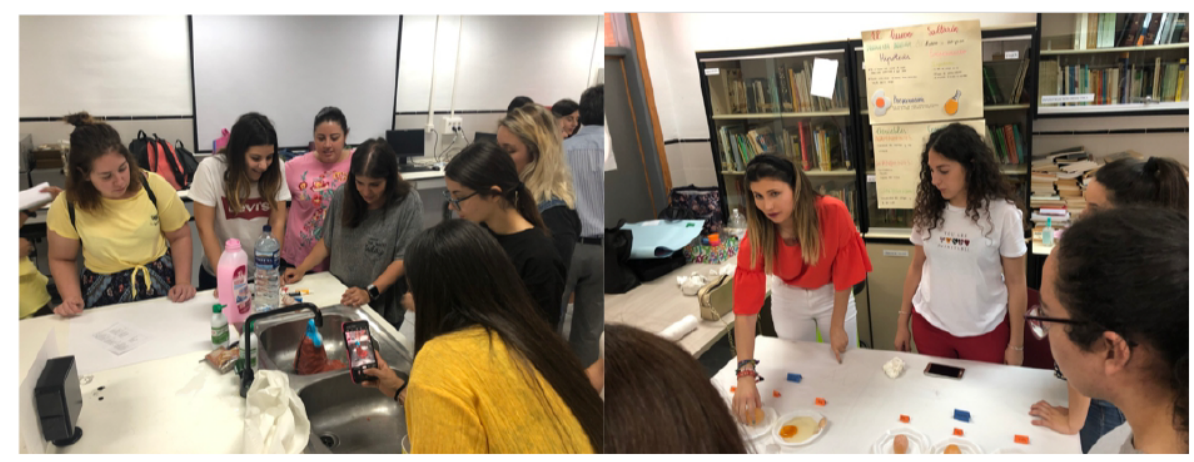

FIGURA 5

EGEIs en la feria de experiencias de indagación

La Tabla 1 describe de forma pormenorizada las etapas formativas del programa académico, las actividades realizadas en cada una de ellas y sus objetivos.

\section{FORMACIÓN PROFESIONAL}

\section{Toma de decisiones y diseño de la propuesta}

Antes del comienzo del Prácticum III, se acordaron las orientaciones para desarrollar la formación profesional del programa formativo. Entre las cuestiones que se valoraron destaca la importancia de utilizar instrumentos adecuados para la toma de datos, así como un seguimiento cuidadoso del proceso, supervisando cada uno de los pasos seguidos y teniendo en cuenta las percepciones de los EGEIs en cuanto a dificultades y emociones sentidas durante esta fase tan importante de su formación.

Una vez asignados los EGEIs a los centros de prácticas, se diseñó un cuestionario para conocer sus expectativas ante el Prácticum, así como su disposición para implementar en los centros secuencias de indagación diseñadas al efecto. Las respuestas de los EGEIs nos permiten ajustar, en la medida de lo posible, las ayudas pedagógicas que necesitan cada uno de ellos, así como facilitar la relaciones con las maestras de EI que serán sus tutoras profesionales. 
TABLA 1

Programa académico. Relación entre etapa formativa, actividades y objetivos

\begin{tabular}{|c|c|c|}
\hline Etapa formativa & Actividades & $\begin{array}{l}\text { Objetivos docentes } \\
\text { (Ayudar a los EGEls a...) }\end{array}$ \\
\hline \multirow[t]{3}{*}{$\begin{array}{l}\text { Presentación del programa } \\
\text { formativo sobre indagación y } \\
\text { recogida de datos iniciales } \\
\text { de los EGEIs }\end{array}$} & $\begin{array}{l}\text { 1.Presentación del programa formativo sobre indagación. Los } \\
\text { profesores explican al grupo clase el programa de la } \\
\text { asignatura en la que se inserta el programa formativo. }\end{array}$ & $\begin{array}{l}\text { Conocer el programa incidiendo } \\
\text { en la indagación. }\end{array}$ \\
\hline & $\begin{array}{l}\text { 2.Primera reflexión individual de los EGEls sobre aprendizaje } \\
\text { y emociones en torno a las etapas de la indagación científica. }\end{array}$ & $\begin{array}{l}\text { Conocer sus emociones iniciales } \\
\text { sobre las etapas de la indagación } \\
\text { antes de participar en el } \\
\text { programa. }\end{array}$ \\
\hline & $\begin{array}{l}\text { 3.Los EGEls responden, de forma individual, a cuestiones } \\
\text { sobre el grado de comprensión de la indagación científica } \\
\text { (Lederman et al. 2014) }\end{array}$ & $\begin{array}{l}\text { Conocer su grado de comprensión } \\
\text { inicial sobre la indagación } \\
\text { científica. }\end{array}$ \\
\hline \multirow[t]{2}{*}{$\begin{array}{l}\text { Realización por parte de los } \\
\text { EGEls de un ciclo completo } \\
\text { de indagación y reflexión } \\
\text { sobre el mismo }\end{array}$} & $\begin{array}{l}\text { 4.Se plantea a los EGEIs realizar un ciclo completo de } \\
\text { indagación. En este caso, se utilizó una propuesta de } \\
\text { indagación sobre la elaboración de yogur (Muñoz-Campos et } \\
\text { al. 2020) que se eligió por su facilidad de realización y la } \\
\text { posibilidad de ser llevado a cabo con niños de El. }\end{array}$ & $\begin{array}{l}\text { Realizar un ciclo completo de } \\
\text { indagación, que muchos de ellos } \\
\text { no han tenido la oportunidad de } \\
\text { hacerla como estudiantes con } \\
\text { anterioridad. }\end{array}$ \\
\hline & $\begin{array}{l}\text { 5.Segunda reflexión individual de los EGEIs sobre aprendizaje } \\
\text { y emociones en torno a las etapas de la indagación científica. }\end{array}$ & $\begin{array}{l}\text { Conocer sus emociones sobre } \\
\text { indagación y reflexionar sobre su } \\
\text { aprendizaje después de haber } \\
\text { vivenciado una indagación. }\end{array}$ \\
\hline $\begin{array}{l}\text { Análisis didáctico de la } \\
\text { indagación realizada }\end{array}$ & $\begin{array}{l}\text { 6.Los EGEIs deben identificar en las actividades desarrolladas } \\
\text { cuáles son los objetivos y contenidos, así como la } \\
\text { contribución a la compresión del problema y al desarrollo de } \\
\text { la indagación. Actuando ahora como maestros/as, se pide } \\
\text { que identifiquen los tipos de aprendizaje que han adquirido } \\
\text { indicando conocimientos, habilidades yactitudes. }\end{array}$ & $\begin{array}{l}\text { Reflexionar sobre lo aprendido } \\
\text { (sobre aspectos didácticos y de } \\
\text { indagación incluidos en la } \\
\text { experiencia realizada) y sobre } \\
\text { cómo lo han aprendido. }\end{array}$ \\
\hline $\begin{array}{l}\text { Ejemplificación de un } \\
\text { proyecto de indagación para } \\
\text { EI }\end{array}$ & $\begin{array}{l}\text { 7.Se facilita a los EGEIs una actividad de indagación realizada } \\
\text { con alumnos de EI para analizarla con la ayuda de una } \\
\text { plantilla. En este caso se utilizó un proyecto sobre el agua } \\
\text { desarrollado con niños de } 3 \text { años (De la Calle 2005). Los ET } \\
\text { realizan un análisis de las diferentes experiencias que } \\
\text { contempla el proyecto para identificar los elementos de la } \\
\text { indagación presentes. En la puesta en común se hace ver a } \\
\text { los EGEls que, aunque el contexto y los temas sean diferentes } \\
\text { (yogur y agua) los elementos de una indagación están } \\
\text { presentes en ambas propuestas. }\end{array}$ & $\begin{array}{l}\text { Reconocer que es posible realizar } \\
\text { actividades de indagación en la } \\
\text { etapa de El, e identificar los } \\
\text { elementos de indagación } \\
\text { presentes en estas propuestas } \\
\text { didácticas. }\end{array}$ \\
\hline $\begin{array}{l}\text { Adaptación de la indagación } \\
\text { sobre el yogur a la etapa de } \\
\text { El }\end{array}$ & $\begin{array}{l}\text { 8.Se facilita a los EGEIs un esquema para diseñar actividades } \\
\text { de indagación adaptadas a El. Utilizando este esquema y } \\
\text { trabajando en ET, deben diseñar una propuesta de } \\
\text { indagación para adaptar, a niños de El, la actividad sobre el } \\
\text { yogur que ellos han realizado como estudiantes. }\end{array}$ & $\begin{array}{l}\text { Facilitar la transposición didáctica } \\
\text { a El de la indagación realizada por } \\
\text { ellos. }\end{array}$ \\
\hline \multirow{2}{*}{$\begin{array}{l}\text { Diseño de proyectos de } \\
\text { indagación paraEl }\end{array}$} & $\begin{array}{l}\text { 9.Los ET diseñan actividades de indagación para la etapa de EI } \\
\text { que impliquen el uso de herramientas TIC y estén } \\
\text { contextualizadas en otros problemas de la vida diaria. }\end{array}$ & $\begin{array}{l}\text { Transferir lo aprendido al diseño } \\
\text { de nuevas actividades de } \\
\text { indagación. }\end{array}$ \\
\hline & $\begin{array}{l}\text { 10.Tercera reflexión individual de los EGEls sobre aprendizaje } \\
\text { y emociones en torno a las etapas de la indagación científica. }\end{array}$ & $\begin{array}{l}\text { Conocer sus emociones sobre } \\
\text { indagación después de la fase } \\
\text { didácticadel programa formativo. }\end{array}$ \\
\hline \multirow[t]{3}{*}{$\begin{array}{l}\text { Exposición de proyectos de } \\
\text { indagación diseñados por los } \\
\text { EGEls }\end{array}$} & $\begin{array}{l}\text { 11.Los EGEls exponen sus proyectos al grupo clase y se } \\
\text { organiza una feria de experiencias de indagación para } \\
\text { intercambiar prácticas entre los dos centros implicados y dar } \\
\text { difusión a los trabajos realizados. En la feria, los ET } \\
\text { participantes, montan un stand en el que presentan un } \\
\text { póster con el diseño de la indagación y muestran los } \\
\text { experimentos realizados. }\end{array}$ & $\begin{array}{l}\text { Realizar una primera } \\
\text { aproximación a la transferencia a } \\
\text { la práctica y a comunicar y } \\
\text { difundir los resultados de la } \\
\text { indagación. }\end{array}$ \\
\hline & $\begin{array}{l}\text { 12.Cuarta reflexión individual de los EGEls sobre aprendizaje } \\
\text { y emociones en torno a las etapas de la indagación científica. }\end{array}$ & $\begin{array}{l}\text { Conocer sus emociones sobre } \\
\text { indagación después de la fase de } \\
\text { transferencia, comunicación y } \\
\text { difusión. }\end{array}$ \\
\hline & $\begin{array}{l}\text { 13.Los ET realizan un informe escrito sobre todo el proceso y } \\
\text { evalúan la puesta en práctica de las actividades diseñadas } \\
\text { formulando propuestas de mejora tanto del diseño como de } \\
\text { su implementación. }\end{array}$ & $\begin{array}{l}\text { Reflexionar y evaluar su práctica } \\
\text { proponiendo acciones de mejora. }\end{array}$ \\
\hline \multirow[t]{2}{*}{$\begin{array}{l}\text { Informe final y recogida de } \\
\text { datos de los EGEIs }\end{array}$} & $\begin{array}{l}\text { 14.De forma individual, los EGEls analizan las ventajas e } \\
\text { inconvenientes del uso de actividades de indagación para el } \\
\text { aprendizaje de las cienciasen la El. }\end{array}$ & $\begin{array}{l}\text { Valorar el uso educativo de la } \\
\text { indagación en la El. }\end{array}$ \\
\hline & $\begin{array}{l}\text { 15.Los EGEls responden, de forma individual, diferentes } \\
\text { cuestiones sobre el grado de comprensión de la indagación } \\
\text { científica. Esto permitirá conocer si han producido cambios } \\
\text { en su nivel de conocimientos sobre la indagación. }\end{array}$ & $\begin{array}{l}\text { Conocer su grado de comprensión } \\
\text { sobre la indagación cientifica tras } \\
\text { participar en el programa } \\
\text { formativo. }\end{array}$ \\
\hline
\end{tabular}




\section{Implementación de la formación profesional}

La Figura 6 muestra el flujograma de la propuesta formativa profesional centrada en la transferencia a la práctica. Los recuadros representan las acciones realizadas por los EGEIs en prácticas. Todas las actividades son individuales, excepto los seminarios que se realizan en el centro de formación de forma grupal y donde se orienta el trabajo de los EGEIs y se aprovecha para intercambiar ideas, expresar dificultades y emociones y reforzar conocimientos.

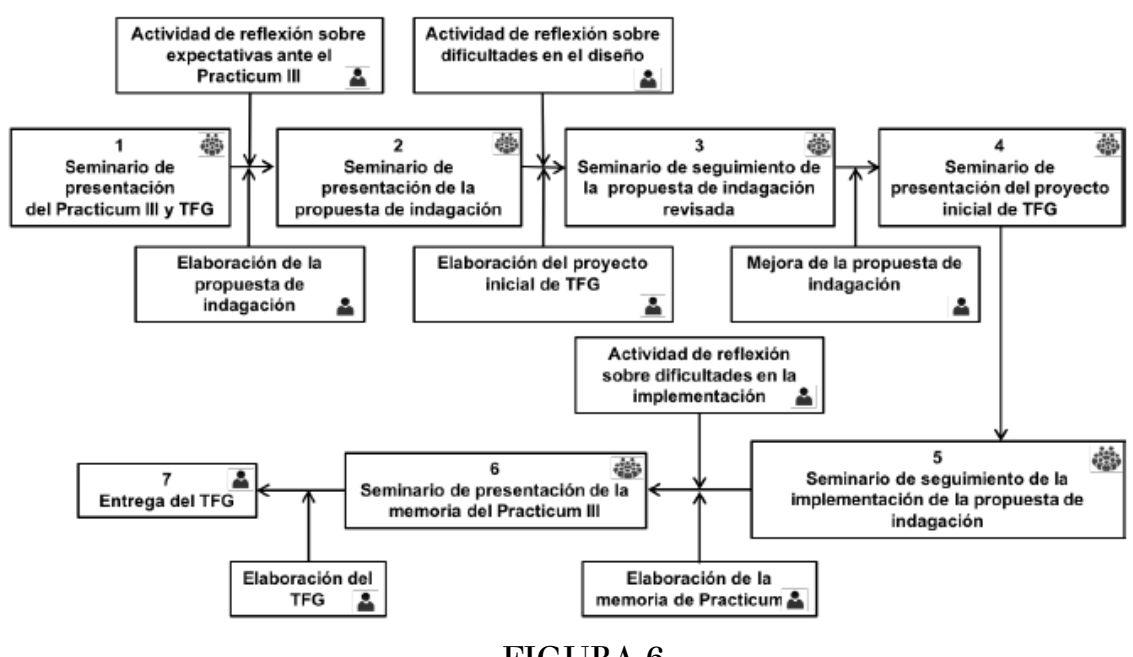

FIGURA 6

Flujograma de la parte profesional del programa formativo sobre indagación

La etapa 1, que constituye la fase de diagnóstico, presenta la propuesta a los EGEIs que van a realizar el Prácticum III y se les pide que reflexionen sobre sus expectativas ante las prácticas externas. En la etapa 2 los EGEIs diseñan una propuesta de indagación que entregan a los tutores académicos para su revisión. Una vez revisada (etapa 3), los EGEIs la mejoran y acuerdan con los tutores profesionales el momento de su implementación en el aula de EI. En la etapa 4, los EGEIs implementan su propuesta y los tutores profesionales realizan observaciones registrándolas en una escala de observación diseñada al efecto para poder ofrecerles una retroalimentación de sus intervenciones. En la etapa 5 los EGEIs elaboran una memoria de prácticas. La evaluación de la propuesta formativa y de su implementación en EI son el tema central de los TFG (etapa 6), constituyendo su entrega la etapa 7.

\section{VALORACIÓN DEL USO DE LA INDAGACIÓN EN EDUCACIÓN INFANTIL POR PARTE DE LOS EGEIS}

Este apartado pretende mostrar los primeros resultados de la utilidad del programa formativo a partir de la valoración que hacen los EGEIs del uso de la indagación en la EI. Se ilustran con ejemplos de respuestas de los EGEIs acompañados de imágenes del trabajo de campo en algunos aspectos que consideramos clave en el uso de indagaciones en el aula. Se muestran también algunos productos obtenidos en forma de póster científico y materiales utilizados en la feria de experiencias de indagación.

El instrumento empleado fue el informe final elaborado por los EGEIs, de forma individual, al término de la formación académica (Tabla 1, actividad 14), en el que recogía la indagación realizada y una reflexión crítica sobre la misma y el programa de formación, y, se pedía, entre otros aspectos, la valoración de las ventajas e inconvenientes del uso de la indagación en EI. Debido a que este informe es un documento muy extenso, así como por el elevado número de participantes (133) del estudio, se decidió analizar una muestra del 30\% 
de los mismos, elegidos al azar entre los dos centros, quedando la muestra constituida por 40 informes, 20 de cada centro participante.

Para el análisis de las valoraciones dadas por los EGEIs en sus informes, se llevó a cabo un análisis inductivo (Dey 2005) de tal forma que las categorías emergieron de las respuestas de los EGEIs, teniendo en cuenta que la finalidad de este análisis era identificar las fortalezas y debilidades del programa formativo. En una primera versión, a partir del análisis de la primera autora se establecieron 20 ventajas y 8 inconvenientes, estos fueron analizadas por el equipo de investigación (los autores del artículo). De esta forma, el esquema de análisis quedó constituido por siete categorías, cuatro de ellas relacionadas con ventajas de la utilización de esta práctica científica y tres con inconvenientes, recogiendo cada una de ellas distintos aspectos. El equipo de investigación realizó de forma individual la categorización de las respuestas y en aquellos casos en los que había discrepancias se trabajó de forma conjunta consensuando la categorización final.

Una vez categorizadas las respuestas, se realizó un análisis descriptivo de las mismas y a continuación, un análisis estadístico inferencial con el programa SPSS para analizar posibles diferencias en las respuestas dadas por los EGEIs de cada centro. Dada la distribución de los datos obtenidos, se utilizaron las pruebas no paramétricas de U de Mann-Whitney para muestras independientes y de los rangos con signo de Wilconxon para muestras relacionadas.

\section{Ventajas del uso de la indagación}

Las ventajas del uso de la indagación planteadas por los EGEIs se agruparon en cuatro categorías: aspectos importantes para el aprendizaje de las ciencias, aspectos generales del aprendizaje, aspectos incluidos en el currículum de EI, y aspectos sociales. La Figura 7 muestra la frecuencia de cada uno de los 20 aspectos identificados, empleando un color distinto para cada centro.

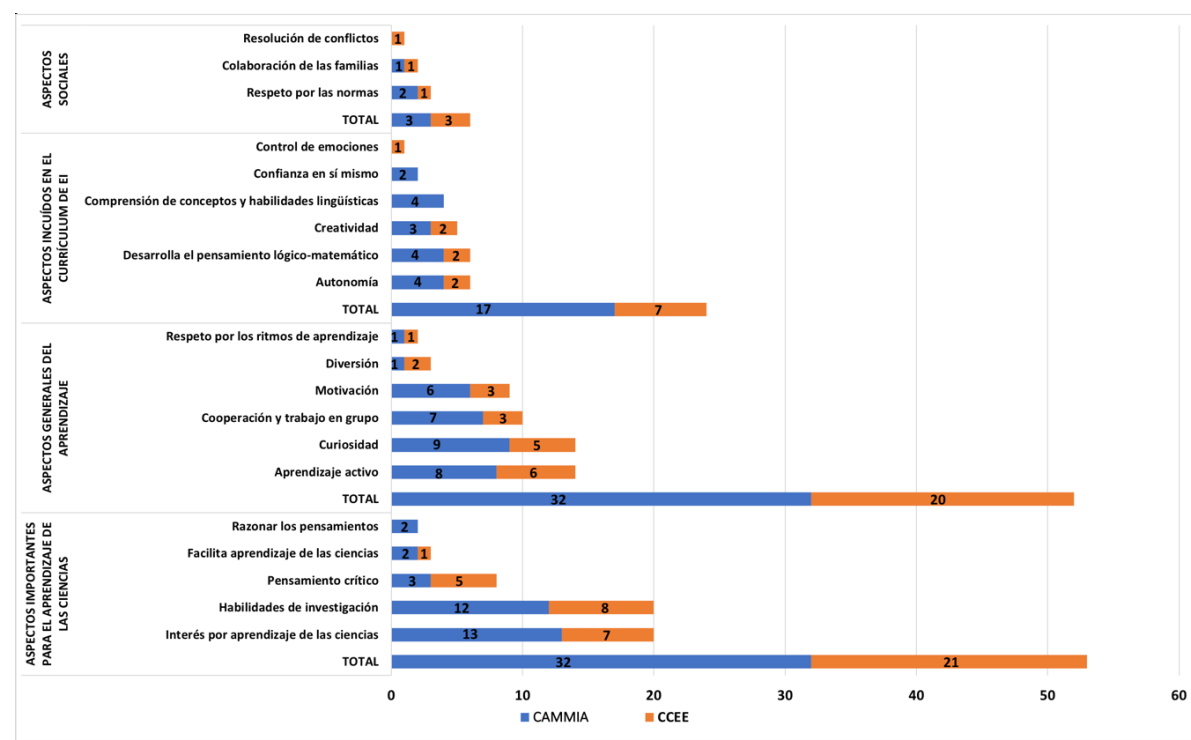

FIGURA 7

Valoraciones de los EGEIs sobre las ventajas del uso de la indagación en EI

Como se observa, las categorías y aspectos más destacados se refieren a los aspectos importantes para el aprendizaje de las ciencias, señalando fundamentalmente el interés por su aprendizaje y el desarrollo de habilidades de investigación; y aspectos generales del aprendizaje, indicando principalmente aprendizaje activo, curiosidad, cooperación y motivación.

A continuación, se presentan algunas respuestas que muestran los aspectos importantes que para los EGEIs tiene a la indagación para el aprendizaje de las ciencias. 
- La indagación como metodología para enseñar y aprender a través de la experimentación: Los EGEIs destacan la importancia de que los niños experimenten en el aula y que los maestros enseñen con metodologías alejadas del uso de fichas, independientemente del trabajo organizativo y de tiempo requeridos:

«Tras haber realizado varias actividades de indagación y vivenciar la feria puedo decir que la idea de emplear la indagación como metodología es realmente enriquecedora para el alumnado de infantil puesto que se adapta mucho a la idea que tengo de una buena enseñanza que no se base solo en fichas y libros, sino que el niño vivenciando y experimentando consigue aprender mucho más».

«La indagación no solo ofrece la oportunidad a los alumnos de aprender de una forma diferente, sino que da la oportunidad a los maestros de enseñar de otra manera más dinámica convirtiéndose en mediadores del aprendizaje.»

«Es cierto que como docente realizar este tipo de actividades requiere muchísimo tiempo y organización, pero pienso que solo hay que ver los resultados que se obtienen para comprender que merece la pena».

- La indagación como práctica para aprender ciencias: Los EGEIs pusieron de manifiesto que la indagación constituye una práctica adecuada para enseñar y aprender de forma significativa cualquier contenido científico:

«A través de la indagación se pueden trabajar todos y cada uno de los contenidos de ciencias de una forma divertida y motivadora que generan gran interés en los alumnos al mismo tiempo que los aprendizajes se vuelven significativos».

Esta idea se ilustra con las imágenes de la Figura 8 que recoge proyectos de indagación sobre temáticas muy diferentes: convección, gases, mezclas, lluvia ácida, crecimiento de las plantas, energía solar, flotabilidad, etc.

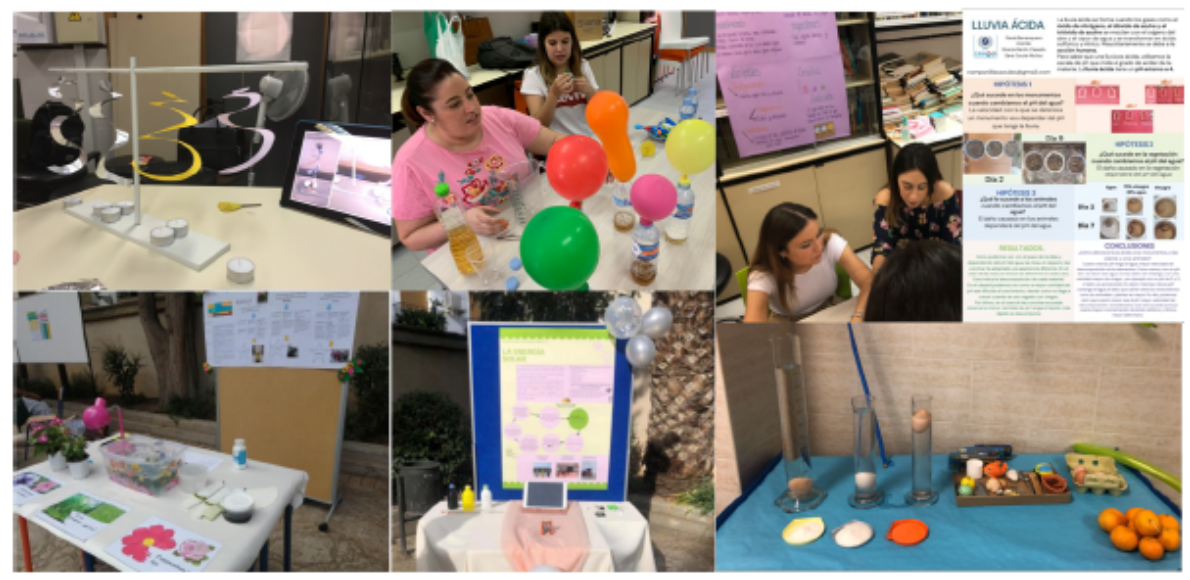

FIGURA 8

Proyectos de indagación desarrolladas por EGEIs sobre diferentes temáticas

El análisis estadístico de las ventajas dadas por los EGEIs de ambos centros muestra diferencias estadísticamente significativas, a favor del centro CAMMIA, en el número total de ellas $(Z=-2,796 ; \mathrm{p}=$ $0,005)$ y también en las categorías de aspectos incluidos en el currículum de EI $(Z=-2,013 ; p=0,072)$ y aspectos generales del aprendizaje $(Z=-2,233 ; p=0,033)$. Sin embargo, las respuestas de ambos grupos son bastante similares en las ventajas concretas, ya que solo aparecen diferencias estadísticamente significativas, siempre a favor de CAMMIA, en la comprensión de conceptos y el desarrollo de habilidades lingüísticas ( $\mathrm{Z}$ $=-2,082 ; \mathrm{p}=0,289)$. 


\section{Inconvenientes del uso de la indagación}

En relación con los inconvenientes, se observó que son menos numerosos que las ventajas. La Figura 9 recoge la frecuencia de los nueve aspectos identificados agrupados en tres categorías: factores contextuales de la enseñanza, curriculo y factores personales relativos al maestro.

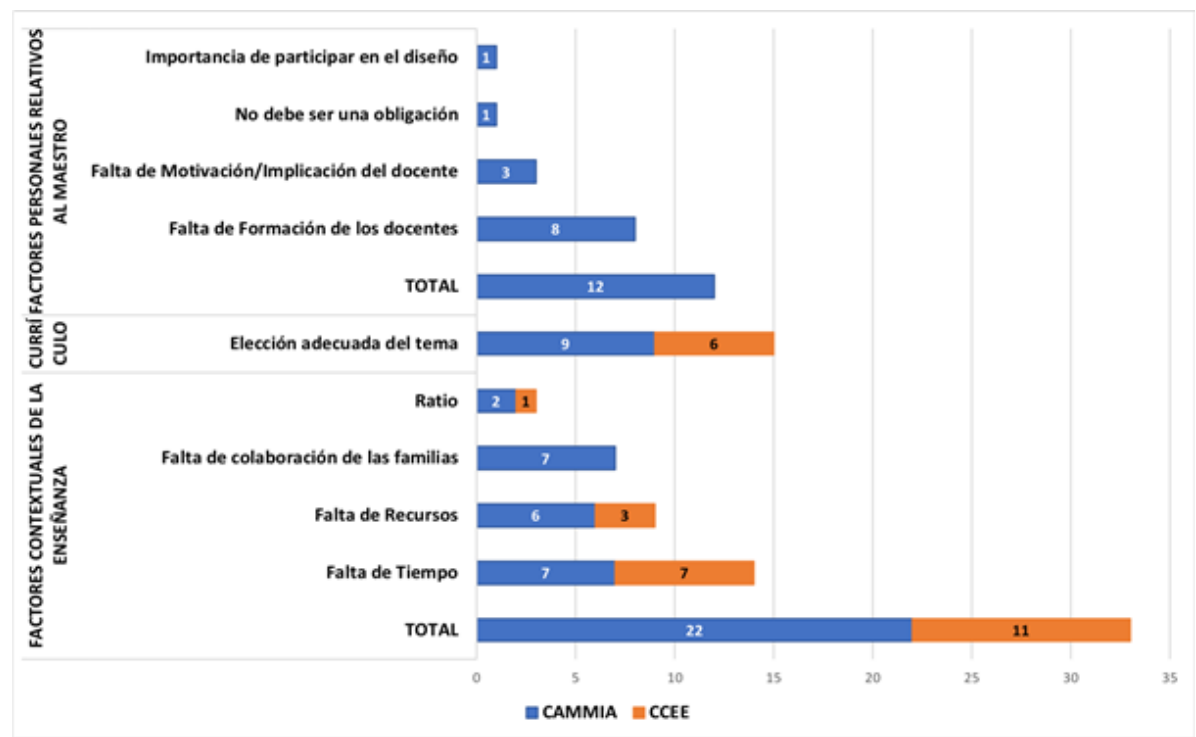

FIGURA 9

Valoraciones de los EGEIs sobre los inconvenientes del uso de la indagación en EI

Como se aprecia en la Figura 9, la categoría en la que más se centraron los EGEIs fue factores contextuales de la enseñanza, y dentro de ella resaltaron la falta de tiempo como un inconveniente importante para llevar a cabo las actividades de indagación en el aula de EI. Los EGEIs también consideraron un inconveniente importante el hecho de que no todos los temas del currículum de EI se prestasen a ser trabajados mediante indagación. Por último, sólo los EGEIs de CAMMIA identificaron inconvenientes relacionados con factores personales relativos al maestro, particularmente a su falta de formación.

Analizando las posibles diferencias en los inconvenientes mostrados por los EGEIs de ambos centros se encontraron diferencias estadísticamente significativas, siempre a favor de CAMMIA, en el número total de inconvenientes $(Z=-2,084 ; p=0,049)$, en los factores personales relativos al maestro $(Z=-3,817 ; p=$ $0,002)$ especialmente en el aspecto relacionado con la falta de formación de los docentes $(Z=-3,122 ; p=$ $0,030)$ y dentro de los factores contextuales de la enseñanza, en la falta de colaboración de las familias $(\mathrm{Z}=$ $-2,876 ; \mathrm{p}=0,060$ ).

En general, se detectan diferencias estadísticamente significativas en el total de ventajas e inconvenientes señalados por los EGEIs de ambos centros $(Z=-4,729 ; p=0,000)$, así como en las indicadas por cada centro de forma independiente (CCEE: $Z=-2,960 ; p=0,003$; CAMMIA: $Z=-3,728 ; p=0,000$ ). Las diferencias entre ambos centros pueden ser debidas al mayor contacto de las EGEIs del CAMMIA con niños de EI, que les había permitido llevar a cabo otras actividades en el desarrollo de las distintas asignaturas, adicionales a las prácticas externas. Estas experiencias parece que les hacen ser capaces de analizar con más detalle los pros y contras del uso de la indagación en la EI. 


\section{Aspectos importantes para su transferencia al aula}

Además de las ventajas e inconvenientes incluidos en las Figuras 7 y 9, los informes de los EGEIs incluían reflexiones importantes sobre aspectos del programa formativo que consideraban importante de cara a su enseñanza en la EI. En particular destacan dos aspectos:

- Vivenciar indagaciones: La mayoría de los EGEIs resaltaron la importancia de vivenciar indagaciones (Figura 10) antes de llevarlas al aula de EI:

«Considero que hay una gran cantidad de ventajas para la utilización de indagaciones debido a que es una metodología vivencial y experimental que es lo que pretende... Puedo confirmar que se aprende mucho más cuando es uno mismo el que investiga y hace las cosas, que si solo te lo cuentan».

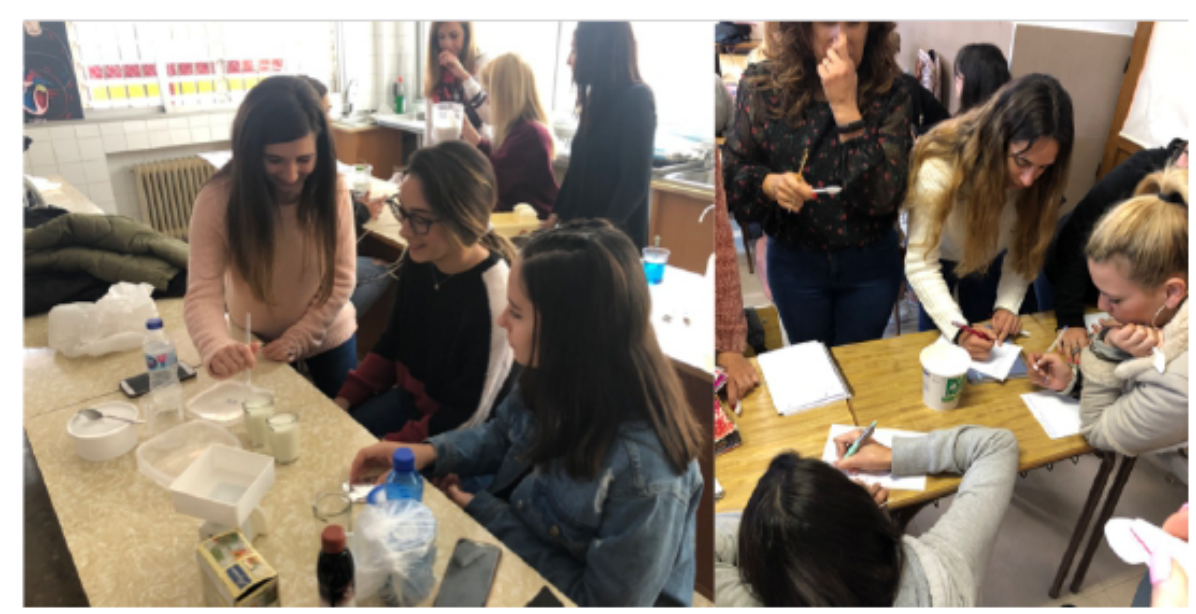

FIGURA 10

EGEIs vivenciando la indagación sobre elaboración de yogur

- Interiorización de las etapas de una indagación: No solo es importante vivenciar indagaciones, sino también interiorizar sus etapas, lo que resulta esencial para entender por qué se realiza cada paso como ilustra este fragmento:

«En relación con la experiencia de indagación realizada en clase sobre el yogur, he aprendido a plantear hipótesis, a observar todas las variables que nos podemos encontrar y a clasificarlas según sean dependientes, independientes o controladas y a evaluar el producto final, entre otros aspectos. Además, me he cuestionado muchos aspectos relacionados con el yogur, como la necesidad o no de consumirlo y he adquirido muchos conocimientos sobre él, como qué ingredientes lo componen, cómo se elabora, los beneficios de consumirlo, etc.»

No obstante, no todos los EGEIs consiguieron esta interiorización de etapas. Este fragmento pone de relieve que, durante la realización de la indagación del yogur, este EGEI no comprendió por qué era necesario añadir un poco de yogur natural (aportación de bacterias para la fermentación) en su elaboración:

«Un inconveniente es que si no sale bien la indagación o no se llega al resultado que queremos conseguir, puede que no queden claros los conceptos a aprender. En mi caso, me pasó con el yogur, ya que ninguno de los tres experimentos salió, y al final no me quedó del todo claro el proceso».

Como síntesis final de las valoraciones, indicar que el hecho de que los EGEIs de ambos centros indicaran, de forma estadísticamente significativa, más ventajas que inconvenientes puede considerarse como un apoyo importante al desarrollo de programas formativos de indagación con EGEIs. El siguiente ejemplo muestra una reflexión sobre qué les puede aportar como futuros maestros el desarrollo de estos programas:

«Puedo afirmar que encuentro más puntos a favor que en contra sobre el uso de actividades de indagación en EI. En mi propia experiencia, puedo confirmar que durante la asignatura he aprendido una gran cantidad 
de contenidos sobre indagación. Al comenzar la asignatura, había oído hablar un poco sobre este tema, pero nada en comparación con lo que ahora sé. Al terminar esta asignatura, puedo confirmar que he aprendido qué es una experiencia de indagación, qué elementos la constituyen y cómo llevar a cabo una indagación en el aula de EI, cómo debo guiarla, qué pasos debo de seguir, etc».

\section{CONSIDERACIONES FINALES}

Los objetivos de este trabajo son presentar un programa formativo desarrollado con EGEIs con el fin de que desarrollen habilidades de indagación que puedan transferir a su práctica con el alumnado de EI, y presentar los resultados de la valoración del uso de la indagación en la EI.

Sobre el primer objetivo, cabe destacar que, si bien la indagación es el eje central de la propuesta, también se trabajan en ella, el trabajo cooperativo entre EGEIs, la reflexión y la metacognición, el diseño de experiencias de indagación para EI, y la comunicación y difusión de dichas experiencias ante sus compañeros. La propuesta combina la formación académica y profesional al igual que los trabajos de Eckhoff (2017) y López-Luengo et al. (2018) aunque aquí se describe en detalle el programa formativo centrado en la indagación y se destaca el acompañamiento llevado a cabo con los EGEIs durante todo el proceso.

Con respecto al segundo objetivo, tras la implementación del programa formativo académico la mayoría de los EGEIs destacaron como ventaja el desarrollo de aspectos importantes para el aprendizaje de las ciencias, principalmente el interés por las mismas y el desarrollo de las habilidades de investigación. Además, la experiencia vivida durante la elaboración y uso de secuencias de indagación, ha favorecido que los EGEIs se involucren en las prácticas científicas (Caamaño 2012) y ha sentado las bases para un posible cambio de modelo didáctico pasando de uno tradicional a otro alternativo donde se fomenta el pensamiento crítico. Los EGEIs también consideran que la indagación favorece el desarrollo de aspectos generales del aprendizaje como el aprendizaje activo, en el sentido que indican Toma et al. (2017), la curiosidad, señalada por Eshach (2006) como fuerza impulsora para aprender ciencias en los primeros años, y facilita la cooperación y el trabajo en grupo.

Por otra parte, los EGEIs consideran que los mayores inconvenientes están relacionados con los factores contextuales de la enseñanza tales como la falta de tiempo, de recursos y de colaboración de las familias. La elección del tema es otro inconveniente para el desarrollo de indagaciones, que debe estar adaptado al nivel madurativo de los niños para favorecer su comprensión y despertar su interés, resultando de esta forma significativo para el niño (Samarapungavan et al. 2008). A su vez, la falta de formación de los docentes para implementar propuestas de indagación en el aula, es considerada por los EGEIs una carencia que ya aparece recogida en la literatura (Mosquera et al. 2018).

Como limitación, este trabajo sólo plantea aspectos concretos de la valoración realizada por los EGEIs sobre la formación recibida. Queda pendiente el análisis del impacto que ha tenido el programa en el cambio de las ideas que tienen los EGEIs sobre la indagación y en sus competencias profesionales para diseñar y llevar a la práctica actividades de indagación en EI.

El análisis de toda la información recogida permitirá rectificar y mejorar el programa formativo para ayudar a los EGEIs durante su formación a diseñar propuestas de indagación que se inserten de forma natural en las temáticas que habitualmente se trabajan en el aula de EI, fomentando el uso de materiales sencillos y reciclables, habituales en las aulas de EI.

\section{Agradecimientos}

Este trabajo forma parte del Proyecto de I $+\mathrm{D}+\mathrm{i}$ del Plan Nacional de España, referencia PID2019-105765GA-I00, titulado «Ciudadanos con pensamiento crítico: Un desafío para el profesorado 
en la enseñanza de las ciencias», financiado por el Ministerio de Ciencia e Innovación en la convocatoria 2019.

\section{ReFERENCIAS}

Aguilera, D., Martín, T., Valdivida, V., Ruiz, Á., Williams, L., Vílchez, J.M. \& Perales, F.J. (2018). La enseñanza de las ciencias basada en indagación. Una revisión sistemática de la producción española. Revista de Educación, 381, 259-294.

Alarcón-Orozco, E. \& Reguero, M.J. (2018). La triple función del docente en situaciones de aprendizaje cooperativo. Ensayos, Revista de la Facultad de Educación de Albacete, 33(2), 63-75.

Alarcón-Orozco, M.M., Franco-Mariscal, A.J. \& Blanco-López, Á. (2019). La indagación en maestros de Educación Infantil en formación inicial. Una propuesta formativa para la transferencia a la práctica. Boletín ENCIC, 3(2), 151-154.

Alarcón-Orozco, M.M., Franco-Mariscal, A.J. \& Blanco-López, Á. (2021). Feria de experiencias de indagación en ciencias en la formación inicial de maestros de educación infantil. Una oportunidad para la transferencia al aula. En D. Cebrián, A.J. Franco-Mariscal, T. Lupión, C. Acebal \& A. Blanco (Coords.), Enseñanza de las ciencias y problemas relevantes de la ciudadanía. (Vol. 23 pp. 173-188). Barcelona: Graó.

Blanco-López, Á. (2019). De la formación inicial de maestros/as a la práctica educativa. La cuestión de la transferencia. Boletin ENCIC, 3(2), 3-7.

Caamaño, A. (2012). ¿Cómo introducir la indagación en el aula? Los trabajos prácticos indagativos. Alambique, Didáctica de las Ciencias Experimentales, 70, 83-91.

Cantó, J., Pro, A. \& Solbes, J. (2016). ¿Qué ciencias se enseñan y cómo se hace en las aulas de educación infantil? La visión de los maestros en formación inicial. Enseñanza de las Ciencias, 34(3), 25-50.

Cañal, P. (2006). La alfabetización científica en la infancia. Aula de Infantil, 33, 5-9.

Crawford, B.A. (2007). Learning to teach science as inquiry in the rough and tumble of practice. Journal of Research in Science Teaching, 44(4), 613-642.

COSCE (2011). Informe ENCIENDE. Enseñanza de las Ciencias en la Didáctica Escolar para edades tempranas en España. Madrid: COSCE. En: http://www.cosce.org/pdf/Informe_ENCIENDE.pdf.

Costillo, E., Borrachero, A.B., Brígido, M. \& Mellado, V. (2013). Las emociones sobre la enseñanza-aprendizaje de las ciencias y las matemáticas de futuros profesores de Secundaria. Revista Eureka sobre Enseñanza y Divulgación de las Ciencias 10, extra, 514-532.

Cruz-Guzmán, M., Puig, M. \& García-Carmona, A. (2020). ¿Qué tipos de actividades diseñan e implementan en el aula futuros docentes de Educación Infantil cuando enseñan ciencia mediante rincones de trabajo? Enseñanza de las Ciencias, 38(1), 27-45.

De la Calle, C. (2005). Proyecto el agua. 3 años. En: https://bit.ly/2tX2lPa

Dey, I. (2005). Qualitative data analysis. A user-friendly guide for social scientific. London: Taylor \& Francis.

Eckhoff, A. (2017). Partners in Inquiry: A Collaborative Life Science Investigation with Preservice Teachers and Kindergarten Students. Early Childhood Education Journal, 45, 219-227.

Erden, T.F. \& Sönmez, S. (2011) Study of Turkish Preschool Teachers' Attitudes toward Science Teaching, International Journal of Science Education, 33(8), 1149-1168.

Eshach, H. (2006). Science literacy in primary schools and pre-schools (Vol. 1). Netherlands: Springer Science \& Business Media.

España, E., Rueda, J.A. \& Blanco, Á. (2013). Juegos de rol sobre el calentamiento global. Actividades de enseñanza realizadas por estudiantes de ciencias del Máster en Profesorado de Secundaria. Revista Eureka sobre Enseñanza y Divulgación de las Ciencias, 10(4), 763-779.

FECYT (2017). Percepción social de la ciencia y la tecnología en España 2016. Madrid: Ministerio de Ciencia e Innovación y FECYT. En: https://bit.ly/364npGt. 
Fleer, M. (2009). Supporting scientific conceptual consciousness or learning in 'a Roundabout way' in play-based contexts. International Journal of Science Education, 31(8), 1069-1089.

Franco-Mariscal, A.J. (2015). Competencias científicas en la enseñanza y el aprendizaje por investigación. Un estudio de caso sobre corrosión de metales en secundaria. Enseñanza de las Ciencias, 33(2), 231-252.

Haefner, A.L. \& Zembal - Saul, C. (2004). Learning by doing? Prospective elementary teachers' developing understandings of scientific inquiry and science teaching and learning. International Journal of Science Education, 26(13), 1653-1674.

Hanuscin, D. L., Lee, M. H., \& Akerson, V. L. (2011). Elementary teachers' pedagogical content knowledge for teaching the nature of science. Science Education, 95(1), 145-167.

Hernández, A.E., Sepúlveda, M.P., Jimeno, M., Ortiz, A.L. \& Pérez, A.I. (2013). El practicum en la formación inicial de los profesionales de la educación: Modelo Marco. Universidad de Málaga.

Lederman, N.G., Lederman, J.S. \& Antink, A. (2013) Nature of science and scientific inquiry as contexts for learning of science and achievement of scientific literacy. International Journal of Education in Mathematics, Science and Technology 1(3), $138-147$.

Lederman, J.S., Lederman, N.G., Bartos, S.A., Bartels, S. L., Meyer, A.A. \& Schwartz, R.S. (2014). Meaningful assessment of learners' understandings about scientific inquiry - The views about scientific inquiry (VASI) questionnaire. Journal of Research in Science Teaching, 51(1), 65-83.

Lederman, J., Lederman, N., Bartels, S., Jimenez, J., Akubo, M., Aly, S., ... Zhou, Q. (2019). An international collaborative investigation of beginning seventh grade students' understandings of scientific inquiry: Establishing a baseline. Journal of Research in Science Teaching, 56(4), 486-515.

López-Gay, R., Jiménez-Liso, M.R., Martínez-Chico, M. \& Castillo, F.J. (2020). Evidencias para la mejora de la enseñanza de las ciencias. Dosier Graó, 5, 39-43.

López-Luengo, M.A., Torrego, L.M. \& Vallés, C. (2018). ¿Cómo se forman los docentes de educación infantil en didáctica de las ciencias? Campo Abierto, Revista de Educación, 37(1), 5-18.

Martínez-Chico, M., Jiménez Liso, M. R., \& López-Gay Lucio-Villegas, R. (2015). Efecto de un programa formativo para enseñar ciencias por indagación basada en modelos, en las concepciones didácticas de los futuros maestros. Revista Eureka sobre Enseñanza y Divulgación de las Ciencias 12(1), 149-166.

Martínez-Chico, M., Jiménez-Liso, M.R. \& Evagorou, M. (2020). Design of a pre-service teacher training unit to promote scientific practices. Is a chickpea a living being? International Journal of Designs for Learning, 11(1), 21-30.

MEC (2007). Real Decreto 1630/2006, de 29 de diciembre, por el que se establecen las enseñanzas mínimas del segundo ciclo de Educación infantil. (BOE, 4, de 4 de enero de 2007, pp. 474-482).

Mesci, G., Schwartz, R.S. \& Pleasants, B.A.S. (2020). Enabling Factors of Preservice Science Teachers' Pedagogical Content Knowledge for Nature of Science and Nature of Scientific Inquiry. Science \& Education, 1-35.

Mosquera, I., Puig, B., \& Blanco, P. (2018). Las prácticas científicas en infantil. Una aproximación al análisis del currículum y planes de formación del profesorado de Galicia. Enseñanza de las Ciencias, 36(1), 7-23.

Muñoz-Campos, V., Franco-Mariscal, A.J. \& Blanco-López, Á. (2020). Integration of scientific practices into daily living contexts: A framework for the design of teaching-learning sequences. International Journal of Science Education, 42(15), 2574-2600.

National Research Council (NRC) (2012). A framework for K-12 science education: Practices, crosscutting concepts, and core ideas. Washington, DC: National Academy Press.

Osborne, J. \& Dillon, J. (Coord.) (2008). Science Education in Europe: Critical Reflections. London: Nuffield Foundation.

Rocard, M. (2007). Science education now: A renewed pedagogy for the future of Europe. Brussels: European Commission. En: https://bit.ly/2UNz86M

Romero-Ariza, M. (2017). El aprendizaje por indagación ¿existen suficientes evidencias sobre sus beneficios en la enseñanza de las ciencias? Revista Eureka sobre Enseñanza de las Ciencias, 14(2), 286-299. 
Sáez, M.J. (2017). Perfiles de maestros en formación ante la enseñanza de las ciencias por indagación. Enseñanza de las Ciencias, extra, 2213-2218.

Samarapungavan, A., Mantzicopoulos, P. \& Patrick, H. (2008). Learning science through inquiry in kindergarten. Science Education, 92(5), 868-908.

Thulin, S. \& Redfors, A. (2016). Student preschool teachers' experiences of science and its role in Preschool. Early Childhood Education Journal, 45(4), 509-520.

Toma, R.B., Greca, I. \& Meneses, J.A. (2017) Dificultades de maestros en formación inicial para diseñar unidades didácticas usando la metodología de indagación. Revista Eureka sobre Enseñanza y Divulgación de las Ciencias, 14(2), 442-457.

Ünver, A. O., Arabacioğlu, S. \& Okulu, H. Z. (2016). Experiencing inquiry with kindergarten: science for kids. En Shelley, M., Kiray, S.A. \& Celik, I. (Eds.) Education Research Highlights in Mathematics, Science and Technology 2016, (pp. 22-31). Iowa, EE.UU.: ISRES Publishing.

Verdugo, J.J., Solaz, J.J. \& Sanjosé, V. (2019). Evaluación del conocimiento científico en maestros en formación inicial: el caso de la Comunidad Valenciana. Revista de Educación, 383, 133-162.

Windschitl, M. (2002). Inquiry projects in science teacher education: What can investigative experiences reveal about teacher thinking and eventual classroom practice? Science Education, 87(1), 112-143.

Worth, K. (2010). Science in early childhood classrooms: Content and process. Conferencia presentada en la Universidad del Norte de Iowa, Estados Unidos. En: http://ecrp.illinois.edu/beyond/seed/worth.html.

Yeigh, T., Woolcott, G., Donnelly, J., Whannell, R., Snow, M., \& Scott, A. (2016). Emotional Literacy and Pedagogical Confidence in Pre-Service Science and Mathematics Teachers. Australian Journal of Teacher Education, 41(6), 107-121.

Zembal-Saul, C. (2009). Learning to teach elementary school science as argument. Science Education, 93(4), 687-719.

\section{Notas}

[1] Este artículo utiliza lenguaje no sexista. Las referencias a personas o colectivos en género masculino se hacen por economía del lenguaje y deben entenderse como un género gramatical no marcado.

[2] Memoria verificada del Grado, disponible en: https://bit.ly/3aM27Bc

[3] Información sobre el TFG, disponible en: https://bit.ly/3e5CCwq

\section{INFORMACIÓN ADICIONAL}

Para citar este artículo: Alarcón-Orozco, M.M., Franco-Mariscal, A.J. y Blanco-López, A. (2022) Ayudando a maestros en formación inicial a desarrollar indagaciones en la Educación Infantil . Revista Eureka sobre Enseñanza y Divulgación de las Ciencias 19(1), 1601. doi: 10.25267/ Rev_Eureka_ensen_divulg_cienc.2022.v19.11.1601 